\title{
Pericytes in the stroma of the rat uterus
}

\author{
Christine Lunam and A. W. Rogers \\ Human Morphology Unit, School of Medicine, Flinders University of South Australia, \\ Bedford Park, South Australia 5042
}

\begin{abstract}
Summary. After ovariectomy and 3 daily injections of progesterone plus one of oestradiol-17 $\beta, 69 \%$ of stromal capillaries of the rat uterus became sheathed with pericytes. On Day 5 of pregnancy the value was 74\% but at other times (Days 4 and 6) and with progesterone-only or no treatment $<15 \%$ of capillaries were associated with pericytes. This period of pericyte presence coincides with the time when implantation is possible.
\end{abstract}

\section{Introduction}

During a morphometric study on the blood vessels of the endometrial stroma of the rat, unexpected variations were observed in the frequency with which pericytes were seen around the capillaries. Preliminary observations suggested that pericytes were present in large numbers in ovariectomized rats treated with a sequence of hormone injections known to permit implantation of donor blastocysts. Psychoyos (1961) has shown that, after three daily injections of progesterone ( $5 \mathrm{mg}$ s.c.) plus a single injection of oestradiol-17 $\beta(0.5 \mu \mathrm{g}$ s.c.) accompanying the third injection, there is a period of 18-24 h, starting $24 \mathrm{~h}$ after the third injection, during which transferred donor blastocysts of suitable age will implant successfully. If this hormone treatment is modified by omitting the oestradiol injection, implantation does not occur.

Pericytes were first described by Rouget (1873), and have since been seen surrounding capillaries in a wide variety of tissues (Majno, 1965; Epling, 1966; Weibel, 1974). They are flattened cells with long cytoplasmic processes closely applied to the capillary endothelial cells. Electron microscopy shows that they are inserted into the basal lamina of the capillary, which splits to enclose them (Majno, 1965). Little is known of their function.

This paper reports counts on the frequency of occurrence of pericytes on stromal capillaries of the endometrium in pregnant rats and ovariectomized rats treated with hormones.

\section{Materials and Methods}

Healthy, young female rats of about $150 \mathrm{~g}$ body weight of the Porton strain were ovariectomized under halothane anaesthesia through flank incisions. During the following 3-4 weeks, the efficacy of ovariectomy was checked by vaginal smears. Three rats were allocated to each of 3 groups: animals in Group 1 received vehicle only; rats in Group 2 received 3 daily subcutaneous (s.c.) injections of $5 \mathrm{mg}$ progesterone; Group 3 rats were similarly treated with progesterone but a single s.c. injection of $0.5 \mu \mathrm{g}$ oestradiol-17 $\beta$ was given at the time of the last progesterone injection. Both progesterone and oestradiol (Sigma Chemical Co.) were dissolved in a mixture of ethyloleate and benzyl alcohol (4:1 v/v). All injections were given between 10:00 and 11:00 h. All animals were killed by ether overdose $24 \mathrm{~h}$ after the last injection. 
Rats, 3 per group, were also killed between 14:00 and 15:00 h on Days 4, 5 and 6 of normal pregnancy. The presence of spermatozoa in the vaginal smear identified Day 1 of pregnancy. In this colony of rats, blastocyst attachment starts on the afternoon of Day 5.

Small blocks of uterus were rapidly dissected out, fixed in a solution of $2.5 \%$ glutaraldehyde and $2.0 \%$ paraformaldehyde in $0.1 \mathrm{M}$-cacodylate buffer $(\mathrm{pH} 7.4)$ and embedded in TAAB resin, using standard procedures. Sections were cut at $0.5 \mu \mathrm{m}$ from 5 blocks of tissue per animal, and stained for light microscopy with toluidine blue. Capillary profiles were counted in the endometrial stroma, and scored for the presence or absence of a recognizable pericyte. Areas for counting were selected on a carefully prearranged basis to sample all areas of the stroma, including mesometrial and antimesometrial. A total of 100 capillaries was counted per rat, using 5 sections, one from each block.

Since variation between rats in any one group proved small, pooled counts from each experimental group were compared directly by Student's $t$ test. A probability $<0.05$ was accepted as significant.

\section{Results}

Pericytes were clearly recognizable in the endometrial stroma as deeply stained, crescentic cells, closely wrapped around the capillary, and differing significantly in shape and position from the nearest stromal cells (Pl. 1, Fig. 2). Electron microscopy confirmed that these pericytes had the expected relationship to the basal lamina of the endothelial cells, which appeared to split to enclose them (Pl. 1, Figs 3 and 4). In Group 1 rats (Pl. 1, Fig. 1), few of the capillary profiles were associated with a pericyte (Table 1), but there was a significant increase in Group 2 and a

Table 1. The percentage (mean \pm s.e.m.) of capillary profiles associated with a pericyte in sections of the endometrial stroma of the rat in different reproductive conditions

\begin{tabular}{llr}
\hline & \multicolumn{1}{c}{ Group } & $\begin{array}{r}\text { \% Capillaries } \\
\text { with pericytes }\end{array}$ \\
\hline 1 & (ovariectomized, no hormones) & $5 \cdot 7 \pm 1 \cdot 18^{\mathrm{a}}$ \\
2 & (ovariectomized, progesterone) & $14 \cdot 7 \pm 2.09^{\mathrm{b}}$ \\
3 & (ovariectomized, progesterone + oestrogen) & $69.0 \pm 6.03^{\mathrm{c}}$ \\
4 & (Day-4 pregnant) & $5.0 \pm 0.98^{\mathrm{a}}$ \\
5 & (Day-5 pregnant) & $74.0 \pm 1.31^{\mathrm{c}}$ \\
6 & (Day-6 pregnant) & $14.0 \pm 1.70^{\mathrm{b}}$ \\
\hline
\end{tabular}

There were 3 rats per group and 100 capillaries counted per rat. Values with different superscript letters were significantly different, $P<0.05$.

\section{PLATE 1}

Fig. 1. Three capillaries in the endometrial stroma of an untreated rat (Group 1): no pericytes are present. Note the small size of the cells and capillaries. $\times 1335$.

Fig. 2. Two capillaries from a rat in Group 3. Pericytes are visible and associated with each profile. Cells and capillaries are much larger than in Group 1 rats. $\times 1335$.

Fig. 3. Electron micrograph of a stromal capillary with an associated pericyte from the uterus of a Group 3 rat. The pericyte is closely applied to the endothelial cell, while extracellular space with collagen fibres lies between the capillary and processes of stromal cells. $\times 7670$.

Fig. 4. High power showing how the basal lamina (arrowed) of the endothelial cell splits to enclose the pericyte. $\times 30000$. 
PLATE
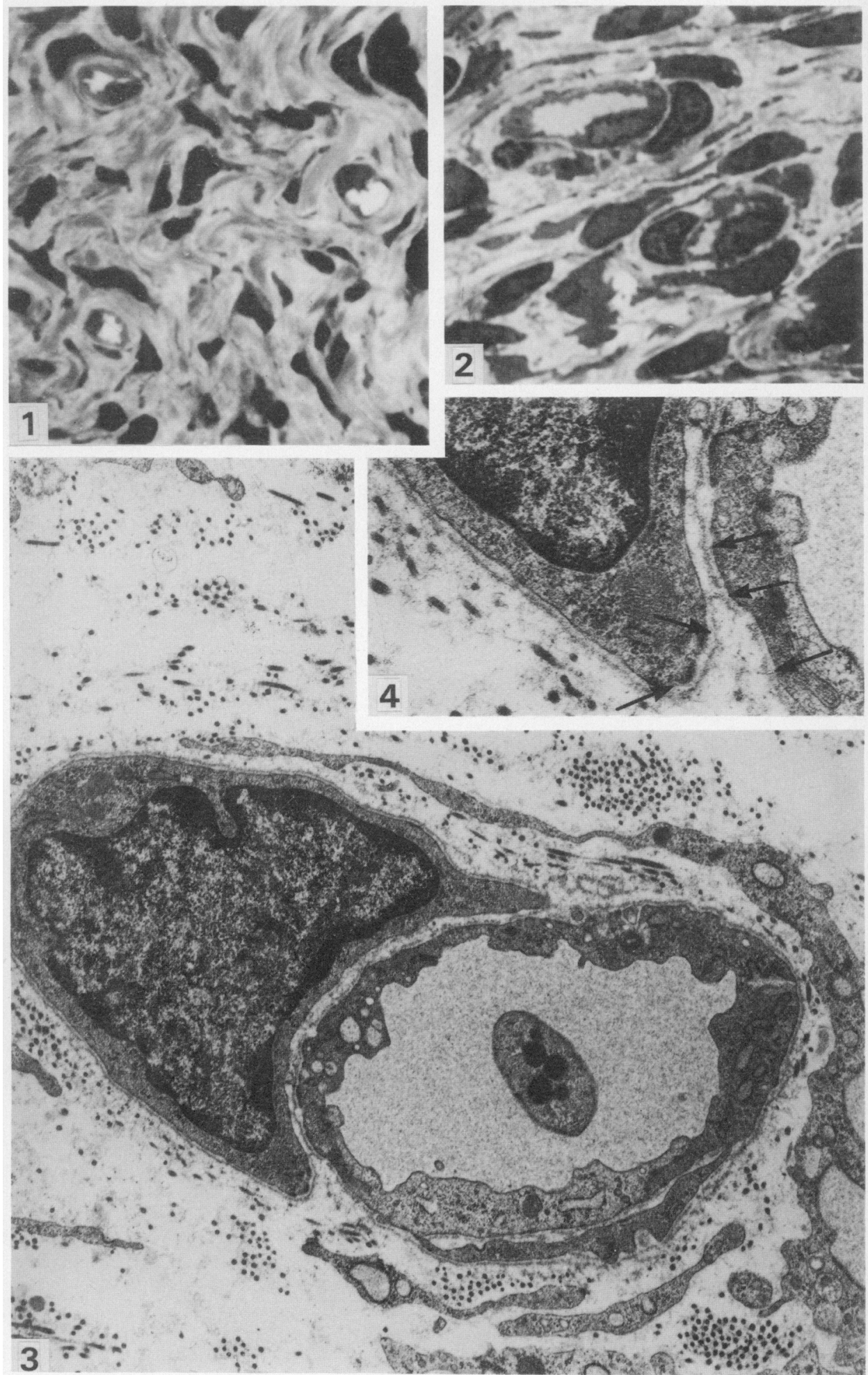
further increase in Group 3 (P1. 1, Fig. 2). The numbers of pericytes in Day-5 pregnant rats were similar to those in rats in Group 3 (Table 1), but the value had fallen considerably by Day 6 of pregnancy.

No association of pericytes with any particular region of the stroma was noted in any of the groups studied: their distribution appeared uniform across the stroma. Seldom was more than one pericyte identified in association with a single capillary profile when the capillary was sectioned transversely: capillary profiles running in the plane of the section often had several pericytes visible.

\section{Discussion}

Since their first description by Rouget (1873), many functions have been suggested for pericytes. Epling (1966) and Weibel (1974) agree with Rouget in attributing to pericytes the physical support of the delicate endothelium, with a further possible function in regulating capillary flow by contraction. In the brain, pericytes have been shown to phagocytose proteins leaked from damaged vessels (Cancilla, Baker, Pollock \& Frommes, 1972). Tedde (1973) has shown that pericytes in the human placenta contain immunoglobulins, and are characterized by dilated cisternae of rough endoplasmic reticulum and many free ribosomes: he suggested that they might synthesize immunoglobulins. In the development of blood vessels in the kitten retina, pericytes appear to differentiate in situ from mesenchymal cells (Shakib \& de Oliveira, 1966): they may represent an early stage in the conversion of capillaries into arterioles and venules in a growing vascular bed. None of these functions seems particularly appropriate to the pericytes of the endometrial stroma.

There is no description in the literature of the rapid appearance and subsequent disappearance of pericytes, such as was noted here between the Day- 4 and Day-5, and Day- 5 and Day- 6 pregnant animals. The presence of a second cell intervening between the endothelial cell and the extracellular space must influence the exchange processes that take place between the blood and the extracellular fluid. It is known that ovarian hormones, particularly oestradiol, affect vascular permeability in the endometrial stroma. Vascular permeability is also significantly increased at implantation sites in the rat uterus. Pontamine blue normally remains within blood vessels when given intravenously. On Days 5 and 6 of pregnancy, however, the dye leaks out into the surrounding stroma at implantation sites. In one animal injected with Pontamine blue, on Day 6 of pregnancy, counts on stromal capillaries at and between implantation sites showed no difference in the frequency of pericytes. It is therefore not possible to relate the presence of pericytes to an increase in vascular permeability.

High pericyte frequencies do, however, correspond well with the ability of the uterus to accept an implanting blastocyst. Of the 6 experimental groups studied, only uteri of the rats in Group 3 and those on Day 5 of pregnancy are compatible with implantation. There are many differences in the appearance of the endometrial stroma in these two groups: in particular, stromal cells appeared larger and the wider capillaries were lined with thicker endothelial cells on Day 5. In spite of these differences, it is possible that this transient sheath of cells, covering nearly two-thirds of the stromal capillary bed, restricts in some way the passage of information between blood and extracellular spaces at the time when an immunologically foreign blastocyst is coming in contact with the luminal epithelium.

It is not easy to see where the pericytes come from between Days 4 and 5 of pregnancy. Pericytes are often recognizable on capillaries in the muscle coat of the uterus in all experimental groups, and some of these may migrate into the stroma. It is equally possible that the stromal cells nearest to the capillaries may migrate towards them, changing in appearance as they do so. Finally, cells from within the blood vessels may migrate through the endothelium to lie closely apposed to it, within the basal lamina: of all the blood cells, only the monocytes resembled the 
pericytes in ultrastructure. The origin and destination of the pericytes forming this transient sheath are difficult to determine without some form of cell labelling.

Implantation is a crucial stage in pregnancy, yet the complex responses of the uterus as it prepares to accept the blastocyst are imperfectly understood, These responses include communication between cells and cell groups, and the transient pericyte sheath may well prove to be one incident in this elaborate sequence of events.

This work was supported by a grant to A.W.R. from the Australian Research Grants Committee.

\section{References}

Cancilla, P.A., Baker, R.N., Pollock, P.S. \& Frommes, S.P. (1972) The reaction of pericytes of the central nervous system to exogenous protein. Lab. Invest. 26, 376-383.

Epling, G.P. (1966) Electron microscopic observations of pericytes of small blood vessels in the lungs and hearts of normal cattle and swine. Anat. Rec. 155, 513-529.

Majno, G. (1965) Ultrastructure of the vascular membrane. In Handbook of Physiology, Vol. III, pp. 2293-2375. Eds W. F. Hamilton \& P. Dow. Am. Physiol. Soc., Washington, D.C.

Psychoyos, A. (1961) Nouvelles recherches sur l'ovoimplantation. C.r. hebd. Séanc. Acad. Sci., Paris 252, 2306-2307.
Rouget, C. (1873) Mémoire sur le développement, la structure et les propriétés physiologiques des capillaires sanguins et lymphatiques. Archs Physiol. Norm. Pathol. 5, 603-663.

Shakib, M. \& de Oliviera, F. (1966) Studies on developing retinal vessels. $X$. Formation of the basement membrane and differentiation of intramural pericytes. Br.J. Ophthalmol. 50, 124-133.

Tedde, G. (1973) Caratteristiche morfologiche dei periciti dei capillari del villo coriale umano e loro ruolo nei fenomeni immunologici materno-fetali. Archo ital. Anat. Embriol. 78, 203-216.

Weibel, E.R. (1974) On pericytes, particularly their existence on lung capillaries. Microvasc. Res. 8, 218-235. 